\title{
Inflammatory Infiltrates in Melanocytic Lesions
}

\author{
Infiltrados Inflamatorios en Lesiones Melanocíticas
}

Alisha Relan'; ${ }^{1}$ Sabina Desar' ${ }^{1}$ Brian Dunnette ${ }^{1}$; Ryan Shanley² \& Alessio Giubellino ${ }^{1,3}$

RELAN, A.; DESAR, S.; DUNNETTE, B.; SHANLEY, R. \& GIUBELLINO, A. Inflammatory infiltrates in melanocytic lesions. Int. J. Morphol., 39(2):512-519, 2021.

SUMMARY: Inflammatory infiltrates are frequently present in melanocytic lesions, with different distribution and composition. Much attention has been devoted to tumor-infiltrating lymphocytes (TIL) in the tumor microenvironment, establishing their prognostic and predictive value in many malignancies, including melanoma. However, lymphocytes, albeit the most numerous and consistent presence, constitute only part of the immune microenvironment. Other inflammatory cells, including neutrophils, plasma cells, eosinophils and mast cells, are found in melanoma and other melanocytic lesions.Few studies offer a detailed count of these inflammatory infiltrates across the spectrum of melanocytic lesions. By using whole slide image analysis and open source software, in the present study we report the enumeration of different inflammatory infiltrates in benign melanocytic nevi, dysplastic nevi, melanoma in situ and invasive malignant melanomas. Significant higher numbers of plasma cells and neutrophils were observed in melanoma. These results indicate that composition of the inflammatory infiltrate may contribute to the diagnostic algorithm of melanocytic lesions.

KEY WORDS: Inflammatory cells; Lymphocytes; Neutrophils; Plasma cells; Nevi; Melanoma.

\section{INTRODUCTION}

A link between inflammation and cancer has been suspected since at least the 18th century, when Rudolf Virchow observed the presence of leukocytes infiltrating neoplastic tissue (Mantovani et al., 2008). But additional studies did not explore in more detail this relationship until the end of the last century(Coussens \& Werb, 2002). Inflammatory infiltrates are frequently present in tumors and their role in oncogenesis and cancer progression is now well established and currently exploited for therapeutic interventions, as more recently highlighted by the success of immunotherapy for a growing number of malignancies (Coussens \& Werb; Ribas \& Wolchok, 2018). In particular, tumor infiltrating lymphocytes (TIL) are well recognized and numerous studies have dissected the function of particular subclasses of these cells and their role in cancer (Hendry et al., 2017a,b), including melanoma (Schatton et al., 2014).

Neutrophils have also been analyzed in detail in several studies, as they are increased in peripheral blood of cancer patients and herald a poor prognosis (Shaul \& Fridlender, 2019). Tumor associated neutrophils (TAN) also appear to have a significant role in oncogenesis and tumor progression, although their role is still controversial, as both pro-tumor and anti-tumor effects have been equally described in the literature (Uribe-Querol \& Rosales, 2015).

Other inflammatory cells, including plasma cells (Fernandez-Flores, 2008; Bosisio et al., 2016), eosinophils (Varricchi et al., 2017a) and mast cells (Biswas et al., 2014; Varricchi et al., 2017b), are found in melanoma and other melanocytic lesions. While numerous studies have explored the composition of specific cells in the inflammatory infiltrate in the tumor microenvironment, few have detailed the enumeration altogether of these inflammatory cells and compared them across the spectrum of different melanocytic lesions, from benign nevi to malignant melanoma.

The vast majority of daily practice diagnoses of melanocytic lesions is performed by morphologic recognition of the lesion in standard hematoxylin and eosin (H\&E) slides. For melanoma in particular the presence of TIL is noted, usually qualitatively as absent, brisk or non-brisk, and this notion has some prognostic value, as a robust lymphocytic reaction is linked to better outcomes (Lee et al., 2016) and response to therapy (Wong et al., 2019).Thus, inflammatory infiltrates are routinely encountered in daily dermatopathology

\footnotetext{
${ }^{1}$ Department of Laboratory Medicine and Pathology, University of Minnesota, Minneapolis, Minnesota 55455, USA.

${ }^{2}$ Masonic Cancer Center Biostatistics Core, University of Minnesota, Minneapolis, Minnesota 55455, USA.

${ }^{3}$ Masonic Cancer Center, University of Minnesota, Minneapolis, Minnesota 55455, USA.
} 
practice. Many cells in these inflammatory infiltrates are sufficiently distinct morphologically to be recognized in routine $H \& E$ sections without the use of immunohistochemistry. Specifically, eosinophils have a bilobed nucleus and a distinct purplish cytoplasm containing finite granules; neutrophils present with a pink cytoplasm and characteristic multilobed nucleus; plasma cell are recognized by an eccentric nucleus in an oval-shaped cell; and finally mast cells have a distinct central nucleus and surrounding granular cytoplasm (Fig. 1). Other components of the infiltrate cannot be distinctly recognized without the use of specific antibodies or special stains. For example, macrophages and resident histiocytes require the use of CD68 antibody for identification, as well as immunohistochemistry is needed to identify dendritic cells and natural killer (NK) cells, all of which are important presence in the tumor microenvironment (Guillerey et al., 2016; Nielsen \& Schmid, 2017; Tucci et al., 2019). Moreover, sub-classification of lymphocytes require the use of immunohistochemistry (e.g. CD4 or CD8 selective antibodies) for more detailed and mechanistic studies.

In the current study, we surveyed inflammatory cells by morphologic recognition, and compared their count distribution across a range of melanocytic lesions, including benign nevi, dysplastic nevi, melanoma in situ and invasive malignant melanoma.

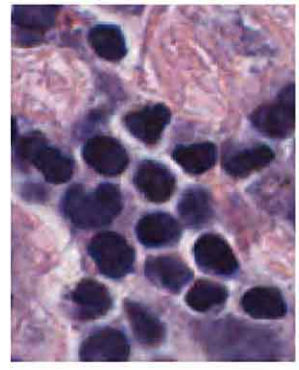

Lymphocytes

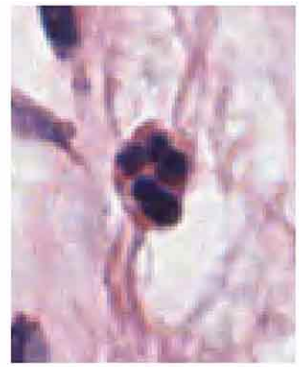

Neutrophil

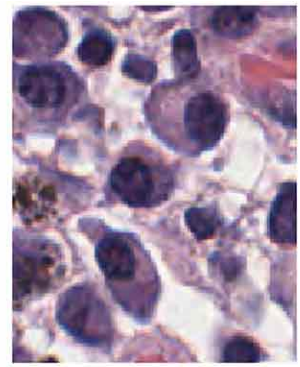

Plasma Cells
MATERIAL AND METHOD

Case Selection and Demographic Data. Slides from six categories of melanocytic lesions were selected from our archive and diagnoses confirmed by a board certified dermatopathologist (AG). Lesions that were incompletely sampled or were ulcerated were excluded from the study. A total of 285 melanocytic lesions were evaluated, including 84 benign nevi (including 12 junctional nevi, 32 compound nevi and 34 intradermal nevi), 118 dysplastic nevi (including 43 with mild, 68 with moderate, 13 with moderate to severe and 4 with severe atypia), 31 melanoma in situ and 52 malignant melanoma) were included in the analysis. Patient demographics were collected including gender, age, anatomic site and summarized in Table I.

Ethics Statement: Following slides selection, patients and case information were de-identified according to IRB protocol (Study \# 2958, University of Minnesota Institution Review Board, last approved 1/2/2020). No informed consent was required for this study.

Scanning, inflammatory cell counting and scoring of tumor infiltrating lymphocytes. Selected slides were scanned at 40X magnification using an Aperio scanner (ScanScope XT, Leica Biosystems, Minneapolis, MN,

Fig. 1. Representative micrographs of the inflammatory cells evaluated in our study: lymphocytes, neutrophils, plasma cells, eosinophils and mast cells.

Table I. Demographic data of the patients analyzed in this study.

\begin{tabular}{lllllll}
\hline & Junctional & Compound & Intradermal & Dysplastic & Melanoma in situ & Malignant melanoma \\
\hline Female & $\mathrm{N}(\%)$ & $\mathrm{N}(\%)$ & $\mathrm{N}(\%)$ & $\mathrm{N}(\%)$ & $\mathrm{N}(\%)$ & $\mathrm{N}(\%)$ \\
$\begin{array}{l}\text { Location } \\
\text { Head/Neck }\end{array}$ & $15(83)$ & $19(59)$ & $26(76)$ & $46(39)$ & $14(45)$ & $24(46)$ \\
$\quad$ Trunk & $5(28)$ & $2(6)$ & $19(56)$ & $0(0)$ & $11(35)$ & $8(15)$ \\
Extremities & $13(72)$ & $10(31)$ & $3(9)$ & $242(20)$ & $8(26)$ & $21(40)$ \\
Age, mean (SD) & $52(15)$ & $41(14)$ & $38(16)$ & $45(15)$ & $67(13)$ & $23(44)$
\end{tabular}

133 mild, 48 moderate, 10 moderate to severe, 3 severe.

210 mild, 10 moderate, 3 moderate to severe, 1 severe.

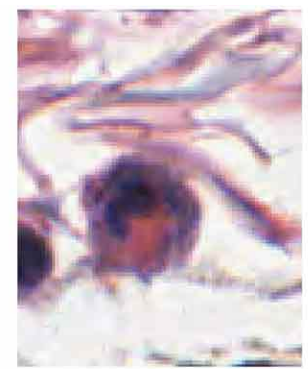

Eosinophil

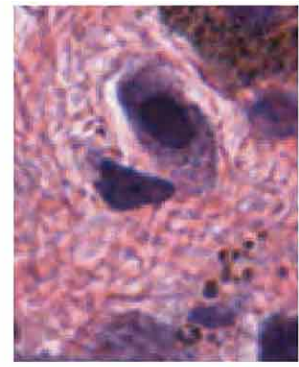

Mast Cell

210 mild, 10 moderate, 3 moderate to severe, 1 severe. 
USA) for further analysis. Digital images were visualized and analyzed using a digital open-source software, QuPath (Bankhead et al., 2017). For each selected histologic section we selected a region of interest (ROI) from the stratum corneum to the bulk of the lesion in the dermis with the inflammatory infiltrate (Fig. 2); as the majority of the lesions included a ROI with a depth of $0.3 \mathrm{~mm}$, a similar depth was kept for lesions with no dermal component (junctional nevi, melanoma in situ). Neutrophils, eosinophils, mast cells, and plasma cells were counted inside the ROI, divided by the area of the ROI and averaged for each category. Representative histologic images of each category of inflammatory cells are shown in Figure 1.

Mean cell counts by lesion category were computed, and their $95 \%$ confidence intervals were calculated using 100 bootstrap resamples due to their asymmetric distributions (the mean has a lower bound of 0 ). First and third quartiles were calculated empirically. The equivalence of distributions across all categories was evaluated by the Kruskal-Wallis test, a non-parametric rank-based null hypothesis test (Tables II and III).
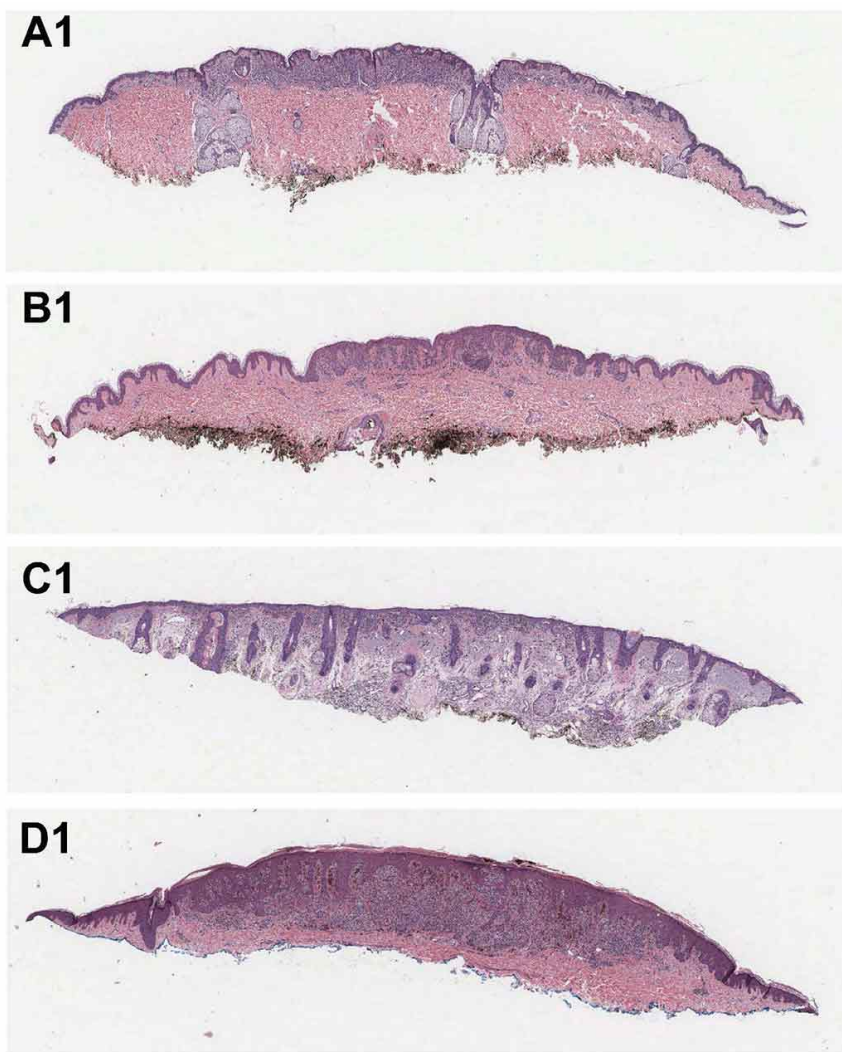

Distributions were also analyzed graphically using boxplots. The box represents the 1st and 3rd quartiles, with a thick horizontal line at the median. Vertical lines extend to the largest and smallest values no more than 1.5 times the interquartile range from the edge of the box. Points outside that range are plotted individually (Figs. 3 and 4).

To quantify the tumor infiltrating lymphocytes, we followed a categorical scoring methodology recently published (Hendry et al., 2017a). Two observers, trained in recognizing lymphocytes in the infiltrate and blinded in their assessment, individually reported TIL values in each respective category of melanocytic lesions and the average of the two values was taken into consideration for analysis. Both intratumoral TIL and peritumoral TIL were assessed and reported interclass correlation coefficients are based on the continuous measure of TIL. Correlation between the two observers is shown with Bland-Altman plots in Figure 5. Two-way intraclass correlation coefficients (ICC) for rater agreement were also calculated.
A2

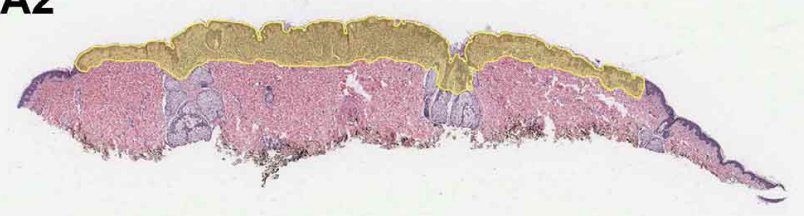

B2

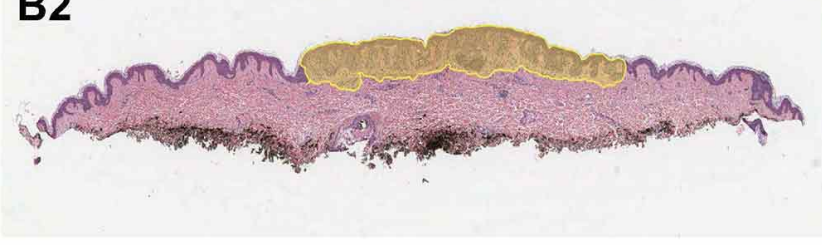

C2

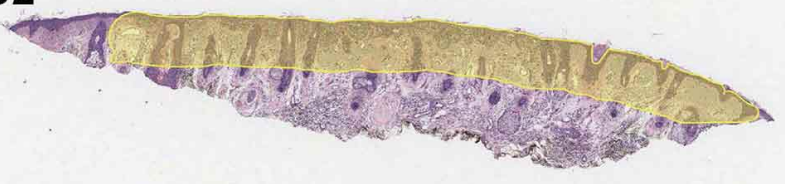

D2

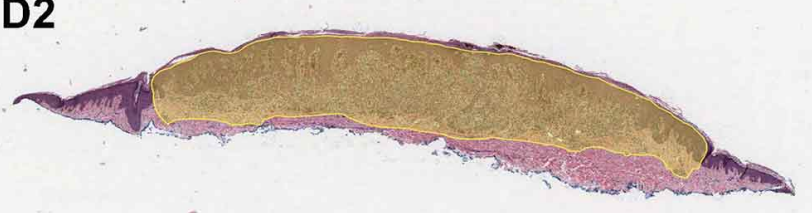

Fig. 2. Representative images of melanocytic lesion and delineation of regions of interest (ROI). Example of compound melanocytic nevus (A1) and relative outline (yellow) of ROI (A2) used for analysis. Similarly are shown a junctional melanocytic nevus (B1, B2), a melanoma in situ $(\mathrm{C} 1, \mathrm{C} 2)$ and a malignant melanoma (D1, D2). 


\section{RESULTS}

Evaluation of tumor infiltrating lymphocytes. We first evaluated a total of 285 melanocytic lesions, including benign nevi, dysplastic nevi, melanoma in situ and invasive melanomas, by selecting a ROI as described in material and methods. Within this region we estimated the presence of TIL and found that dysplastic nevi, melanoma in situ and malignant melanoma present with higher values of TIL when compared with benign nevi. Interestingly, overall, malignant melanoma demonstrates higher values among all the categories of melanocytic lesions evaluated (Table II). This difference was largest in intra tumoral TIL in which the mean of the malignant melanoma group (0.25) was twice as high as either melanoma in situ (0.12) or dysplastic nevi (0.13). Data are shown as boxplots in Figure 3, with each observation representing the mean of the two raters' measurements. Raters' agreement analysis is shown in Figure 5, withan intraclass correlation coefficient of 0.85 for peritumoral TIL and 0.81 for intratumor TIL.

Evaluation of other inflammatory infiltrates. We then evaluated the other inflammatory infiltrates in the same lesions. Similarly to the results obtained for TILs, neutrophil counts were significantly higher in dysplastic nevi,

Table II. Tumor infiltrating lymphocyte (TIL) values across the six categories of melanocytic lesions.

\begin{tabular}{|c|c|c|c|c|c|c|c|}
\hline & $\begin{array}{c}\text { Junctional } \\
\qquad(\mathrm{N}=18)\end{array}$ & $\begin{array}{l}\text { Compound } \\
(\mathrm{N}=32)\end{array}$ & $\begin{array}{c}\text { Intradermal } \\
(\mathrm{N}=34)\end{array}$ & $\begin{array}{c}\text { Dysplastic } \\
(\mathrm{N}=118)\end{array}$ & $\begin{array}{l}\text { Melanoma In } \\
\text { Situ }(N=31)\end{array}$ & $\begin{array}{c}\text { Malignant } \\
\text { Melanoma } \\
(\mathrm{N}=52)\end{array}$ & $\mathrm{p}$ value \\
\hline TIL (Peritumoral) & & & & & & & $<0.001$ \\
\hline Mean & 0.064 & 0.075 & 0.024 & 0.21 & 0.17 & 0.29 & \\
\hline $95 \%$ CI for Mean & $0.05,0.08$ & $0.04,0.11$ & $0.01,0.04$ & $0.19,0.24$ & $0.12,0.24$ & $0.25,0.33$ & \\
\hline 1st, 3rd Quartiles & $0.04,0.09$ & $0.02,0.08$ & $0.01,0.04$ & $0.10,0.28$ & $0.06,0.22$ & $0.17,0.40$ & \\
\hline TIL (Intratumoral) & & & & & & & $<0.001$ \\
\hline Mean & 0.02 & 0.053 & 0.036 & 0.13 & 0.12 & 0.25 & \\
\hline $95 \%$ CI for Mean & $0.01,0.03$ & $0.04,0.07$ & $0.02,0.05$ & $0.11,0.15$ & $0.08,0.16$ & $0.22,0.29$ & \\
\hline $1^{\text {st, }}$ 3rd Quartiles & $0.01,0.02$ & $0.02,0.07$ & $0.01,0.05$ & $0.06,0.17$ & $0.05,0.14$ & $0.15,0.34$ & \\
\hline
\end{tabular}

Table III. Counts (per unit area) of inflammatory infiltrate in melanocytic lesions: neutrophils, plasma cells, eosinophils and mast cells.

\begin{tabular}{|c|c|c|c|c|c|c|c|}
\hline & $\begin{array}{c}\text { Junctional } \\
(\mathrm{N}=18)\end{array}$ & $\begin{array}{l}\text { Compound } \\
(\mathrm{N}=32)\end{array}$ & $\begin{array}{c}\text { Intradermal } \\
(\mathrm{N}=34)\end{array}$ & $\begin{array}{c}\text { Dysplastic } \\
(\mathrm{N}=118)\end{array}$ & $\begin{array}{l}\text { Melanoma In } \\
\text { Situ }(\mathrm{N}=31)\end{array}$ & $\begin{array}{c}\text { Malignant } \\
\text { Melanoma } \\
(\mathrm{N}=52)\end{array}$ & $\mathrm{p}$ value \\
\hline Neutrophils & & & & & & & $<0.001$ \\
\hline Mean & 0.067 & 0.37 & 0.38 & 1.4 & 2.2 & 2.9 & \\
\hline $\begin{array}{c}95 \% \text { CI for } \\
\text { Mean }\end{array}$ & $0.00,0.17$ & $0.03,1.09$ & $0.20,0.64$ & $0.90,2.09$ & $1.11,3.65$ & $2.02,4.05$ & \\
\hline $\begin{array}{c}\text { 1st, 3rd } \\
\text { Quartiles }\end{array}$ & $0.00,0.00$ & $0.00,0.00$ & $0.00,0.54$ & $0.00,1.43$ & $0.00,2.48$ & $0.15,4.51$ & \\
\hline Eosinophils & & & & & & & $<0.001$ \\
\hline Mean & 0 & 0.23 & 0.03 & 0.26 & 0.31 & 0.32 & \\
\hline $\begin{array}{c}95 \% \text { CI for } \\
\text { Mean }\end{array}$ & $0.00,0.00$ & $0.03,0.69$ & $0.00,0.12$ & $0.12,0.40$ & $0.16,0.52$ & $0.20,0.50$ & \\
\hline $\begin{array}{c}\text { 1st, 3rd } \\
\text { Quartiles }\end{array}$ & $0.00,0.00$ & $0.00,0.00$ & $0.00,0.00$ & $0.00,0.00$ & $0.00,0.42$ & $0.00,0.41$ & \\
\hline Plasma Cells & & & & & & & $<0.001$ \\
\hline $\begin{array}{c}\text { Mean } \\
95 \% \text { CI for } \\
\text { Mean }\end{array}$ & $\begin{array}{c}0.8 \\
0.00,2.63\end{array}$ & $\begin{array}{c}0.14 \\
0.03,0.25\end{array}$ & $\begin{array}{c}0.052 \\
0.00,0.12\end{array}$ & $\begin{array}{c}0.28 \\
0.09,0.46\end{array}$ & $\begin{array}{c}1.6 \\
1.09,2.48\end{array}$ & $\begin{array}{c}6.4 \\
1.04,13.04\end{array}$ & \\
\hline $\begin{array}{c}\text { 1 st, 3rd } \\
\text { Quartiles }\end{array}$ & $0.00,0.00$ & $0.00,0.00$ & $0.00,0.00$ & $0.00,0.00$ & $0.00,3.11$ & $0.00,2.35$ & \\
\hline Mast Cells & & & & & & & $<0.001$ \\
\hline $\begin{array}{c}\text { Mean } \\
95 \% \text { CI for } \\
\text { Mean }\end{array}$ & $\begin{array}{c}0.24 \\
0.00,0.71\end{array}$ & $\begin{array}{c}0.25 \\
0.00,1.01\end{array}$ & $\begin{array}{c}0.049 \\
0.00,0.17\end{array}$ & $\begin{array}{c}0.19 \\
0.09,0.30\end{array}$ & $\begin{array}{c}0.49 \\
0.17,1.07\end{array}$ & $\begin{array}{c}0.3 \\
0.14,0.55\end{array}$ & \\
\hline $\begin{array}{c}\text { 1st, 3rd } \\
\text { Quartiles }\end{array}$ & $0.00,0.00$ & $0.00,0.00$ & $0.00,0.00$ & $0.00,0.00$ & $0.00,0.59$ & $0.00,0.15$ & \\
\hline
\end{tabular}


melanoma in situ and malignant melanoma when compared with benign nevi, with the highest median value in malignant melanoma (Table III and Figure 4, panel A). A majority of eosinophil counts were 0 in all lesion types; however approximately $40 \%$ had positive counts in melanoma in situ and invasive melanoma, versus $<17 \%$ for other types (Table III and Figure 4, panel B). With respect to plasma cell counts, we found that both melanoma in situ and malignant melanoma have higher median values, with over half of cases in those categories being positive versus $<20 \%$ for benign and dysplastic nevi (Table III and Figure 4, panel C). The interquartile range of malignant melanoma mostly overlaps with melanoma in situ, although all three cases with very high plasma cell counts were malignant melanoma.
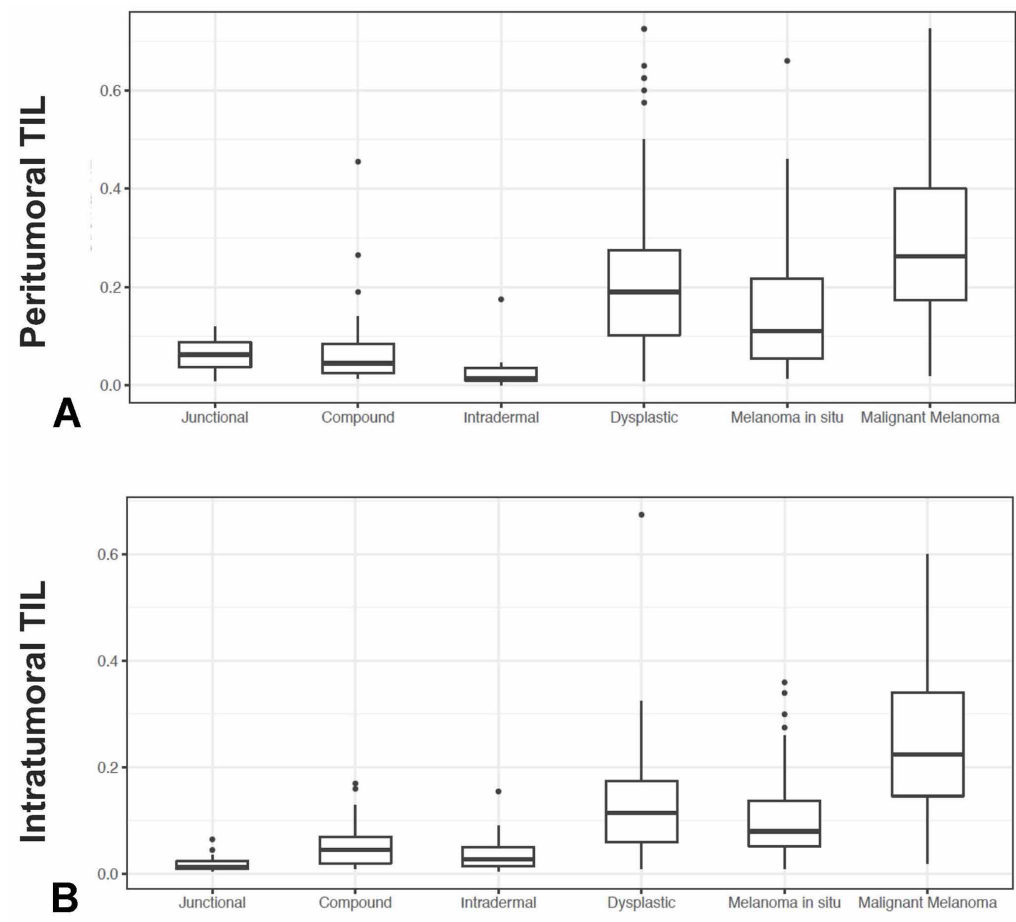

Fig. 3. Boxplot representation, representing themean of the two raters measurement for both peritumoral TIL (panel A) and intratumor TIL (panel B).
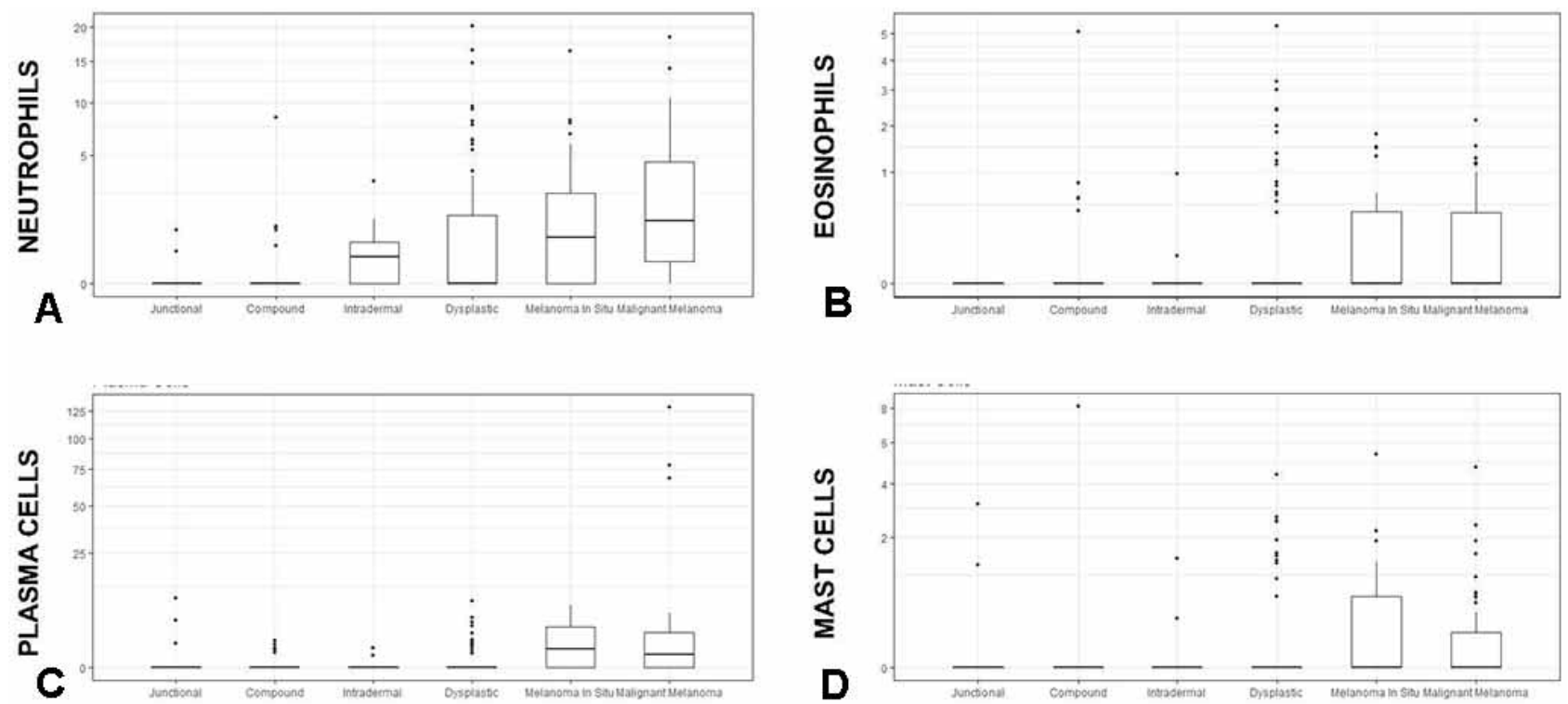

Fig. 4. Boxplot representation, representing thecounts per unit area of neutrophils (A), eosinophils (B), plasma cells (C) and mast cells (D), across the six categories of melanocytic lesions evaluated. 
The distribution of mast cells counts followed a similar pattern as eosinophils, with the majority of cell counts being 0 , but more positive cell counts in melanoma in situ and malignant melanoma (Table III and Figure 4, panel D).
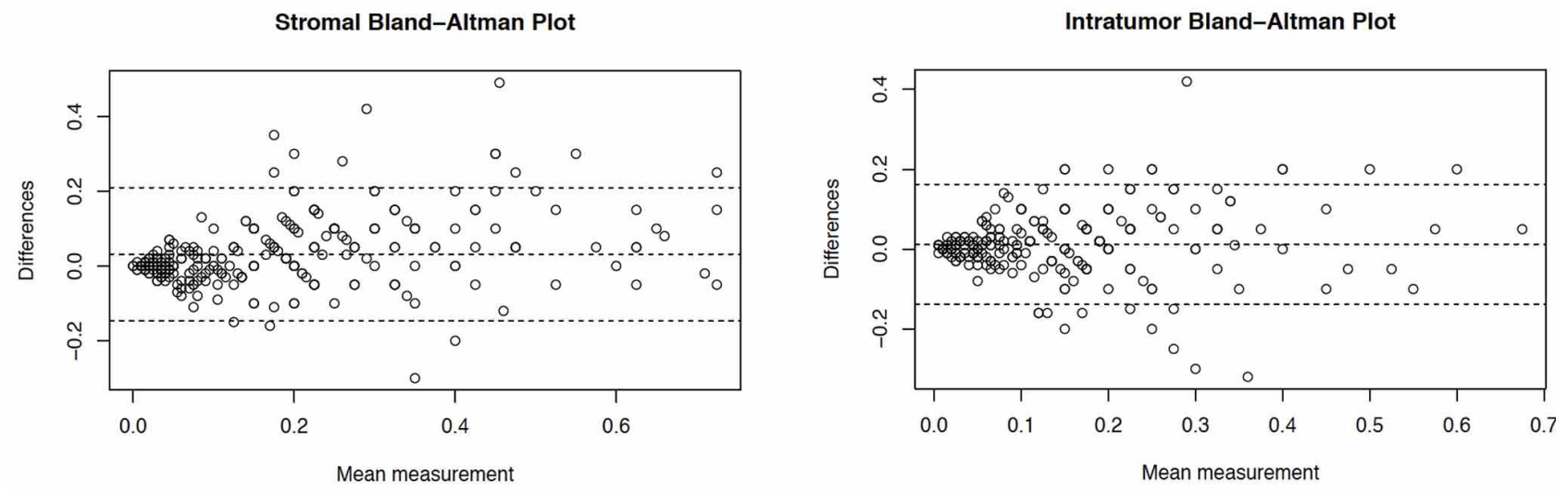

Fig. 5. Stromal and Intratumor Bland-Altman plots, representing the variability between two blinded observers.

\section{DISCUSSION}

Inflammatory infiltrates are commonly found in melanocytic lesions and they have been recognized as a hallmark of cancer (Mantovani et al.). Numerous studies have dissected their function in the tumor microenvironment and are now in use as prognostic and predictive cues. In particular, lymphocytes in the tumor microenvironment (TIL) are well-recognized players in the host response to malignancies. In melanoma, the lymphocytic infiltrate is routinely scored in a qualitative way (Scolyer et al., 2020), and represents an important prognostic parameter (Azimi et al., 2012). A variety of different semiquantitative and quantitative scoring systems for TILs have been proposed (Schatton et al.), none of which appears to have gained broad adoption. In our study we have used a continuous measure of TIL. The relatively high kappa score obtained in our study, suggest that this classification scheme has a good level of inter-observer agreement and appears to be relatively simple and reproducible to be implemented in common practice.

The importance of lymphocytes' scoring is further highlighted by increasing requests by clinicians to include this parameter in final pathology reports, and underscore the increasing need to quantify their presence in a more precise and quantitative fashion, also with the use of current imaging and software technologies (Klauschen et al., 2018), which may overcome earlier problems of standardization across different institutions.

Moving beyond TILs, our study has enumerated other inflammatory cells. Similar to the results obtained with TILs, we found that neutrophils are more numerous in melanoma, both when confined to the epidermis (in situ) and when invasive, but also in the intermediate category of dysplastic nevi, which is now recognized as a true biological precursor lesion in the evolution to malignant melanoma (Shain et al., 2015). There is now a large body of experimental and clinical evidence implicating neutrophils in tumorigenesis and tumor progression. Initial clinical observations highlighted accumulation of neutrophils in the peripheral circulation of oncologic patients, especially in advanced stages of their disease (Schmidt et al., 2005; Mishalian et al., 2017). Further prognostic value has been established in the neutrophil-to-lymphocyte ratio, with implication also to response to therapy. Neutrophils are found in a large variety of human cancer (Gentles et al., 2015), as tumor-associated neutrophils (TANs), but there is still debates on the exact role of TANs in tumors, as both pro-tumor and anti-tumor effects have been demonstrated in different tumors (Shaul \& Fridlender). Of note, we specifically excluded ulcerated lesions from our study, as ulceration by itself can be responsible for accumulation of neutrophils by exposing cutaneous tissue to the pathogens in the external environment.

While the role of T cells is well established, less is known about the role of B lymphocytes as contributors to the immune tumor microenvironments (Nelson, 2010). Plasma cells are terminally differentiated B cells that synthesize and secrete antibodies and provide humoral immunity. Plasma cells are frequently seen in melanoma and in halo nevi, and may be a useful "soft" features to distinguish a melanoma from a nevus in the appropriate context, or predict 
the occurrence of lymph node metastases. Indeed, the presence of plasma cells in melanoma has been linked to poor outcomes (Bosisio et al.). In a study of more than seven hundred melanomas, lesions enriched in plasma cells were found to have worst histopathologic parameter, such as higher tumor thickness, mitotic rate and presence of ulceration, and had a less favorable prognosis (Bosisio et $a l$.). Our data demonstrated higher value in plasma cell count in melanoma compared with benign nevi and dysplastic nevi, further reinforcing their importance in the tumor microenvironment.

In our study we found that eosinophils and mast cell counts were mostly zero across the several categories of melanocytic lesions evaluated. However, if we subdivide melanocytic nevi in the three categories analyzed we see that dysplastic nevi and melanomas appears to have a higher percentage of positive cell counts when compared to benign nevi. Prior studies have evaluated the role of eosinophils in the tumor microenvironment. Collectively, their role appears to be dependent on the type of tumor considered, as some studies have revealed a protective role in some cancers, such as in melanoma, where their presence appears to correlate positively with response to immunotherapy and longer survival (Weide et al., 2016; Moreira et al., 2017); while other studies have revealed a pro-tumoral effect, such as in Hodgkin's lymphoma (von Wasielewski et al., 2000) and cervical cancer (Xie et al., 2015), where eosinophils heralds a poor prognosis or poor response to therapy.

A limitation of this study is the use of morphology alone for the identification of inflammatory infiltrates without the aid of immunohistochemistry markers. This has limited the types of inflammatory cells that we were able to recognize on morphologic ground only. For example it is not possible to only morphologically recognize macrophages, as mentioned before, which are certainly an important player in melanoma and other melanocytic lesions. However, the inflammatory cells enumerated in this article have sufficiently distinct histologic features, as mentioned earlier, for a confident assessment on routine hematoxylin and eosin (H\&E) stained samples. Other studies from the literatures have enumerated single classes of inflammatory cells using specific antibodies (e.g. mast cell tryptase or CD117 for highlighting mast cells). The use of immunohistochemistry indubitably more specifically allow to recognize and count these cells and appears to allow for recognition of a larger number of cells, as noted in other articles. However, in common practice would be unpractical to stains all specimens to highlight each inflammatory component; so, our approach to quantify cells on $\mathrm{H} \& \mathrm{E}$ section is arguably more practical and potentially close to daily practice.
Overall, numerous studies have explored the role of inflammatory infiltrate in cancer, outlining the prominent role of different inflammatory cells in tumorigenesis, tumor progression and prognosis. These studies have resulted in innovative and efficacious therapies, as the relatively recent success of immunotherapies have clearly demonstrated. Attention to the diversity of the inflammatory infiltrate in melanocytic lesions can aid in a correct classification and diagnosis, and possibly, guide further clinical management including selection of the appropriate course of treatment. Additional studies on a larger cohort of samples may help to better refine and expand on the result from our study.

\section{ACKNOWLEDGMENTS}

This work was supported by start-up funds from the Department of Laboratory Medicine and Pathology/Masonic Cancer Center, University of Minnesota. Research reported in this publication was also supported by NIH grant P30 CA77598 utilizing the Biostatistics and Bioinformatics Core shared resource of the Masonic Cancer Center, University of Minnesota and by the National Center for Advancing Translational Sciences of the National Institutes of Health Award Number UL1TR002494. The content is solely the responsibility of the authors and does not necessarily represent the official views of the National Institutes of Health.

RELAN, A.; DESAR, S.; DUNNETTE, B.; SHANLEY, R. \& GIUBELLINO, A. Infiltrados inflamatorios en lesiones melanocíticas. Int. J. Morphol., 39 (2):512-519, 2021.

RESUMEN: Los infiltrados inflamatorios están presentes con frecuencia en las lesiones melanocíticas, con diferente distribución y composición. Se ha prestado mucha atención a los linfocitos infiltrantes de tumores (TIL) en el microambiente tumoral, estableciendo su valor pronóstico y predictivo en muchas neoplasias malignas, incluido el melanoma. Sin embargo, los linfocitos de presencia más numerosa y constante, constituyen solo una parte del microambiente inmunológico. Otras células inflamatorias, incluidos neutrófilos, células plasmáticas, eosinófilos y mastocitos, se encuentran en el melanoma y otras lesiones melanocíticas. Pocos estudios ofrecen un recuento detallado de estos infiltrados inflamatorios en todo el espectro de lesiones melanocíticas. Mediante el uso de análisis de imágenes de diapositivas completas y software de código abierto, en el presente estudio informamos la enumeración de diferentes infiltrados inflamatorios en nevos melanocíticos benignos, nevos displásicos, melanoma in situ y melanomas malignos invasivos. Se observaron números significativamente más altos de células plasmáticas y neutrófilos en el melanoma. Estos resultados indican que la composición del infiltrado inflamatorio puede contribuir al algoritmo diagnóstico de las lesiones melanocíticas. 
PALABRAS CLAVE: Células inflamatorias; Linfocitos; Neutrófilos; Células de plasma; Nevi; Melanoma.

\section{REFERENCES}

Azimi, F.; Scolyer, R. A.; Rumcheva, P.; Moncrieff, M.; Murali, R.; McCarthy, S. W.; Saw, R. P. \& Thompson, J. F. Tumor-infiltrating lymphocyte grade is an independent predictor of sentinel lymph node status and survival in patients with cutaneous melanoma. J. Clin. Oncol., 30(21):2678-83, 2012.

Bankhead, P.; Loughrey, M. B.; Fernández, J. A.; Dombrowski, Y.; McArt, D. G.; Dunne, P. D.; McQuaid, S.; Gray, R. T.; Murray, L. J.; Coleman, H. G.; et al. QuPath: Open source software for digital pathology image analysis. Sci. Rep., 7(1):16878, 2017.

Biswas, A.; Richards, J. E.; Massaro, J. \& Mahalingam, M. Mast cells in cutaneous tumors: innocent bystander or maestro conductor? Int. J. Dermatol., 53(7):806-11, 2014.

Bosisio, F. M.; Wilmott, J. S.; Volders, N.; Mercier, M.; Wouters, J.; Stas, M.; Blokx, W. A.; Massi, D.; Thompson, J. F.; Scolyer, R. A.; et al. Plasma cells in primary melanoma. Prognostic significance and possible role of IgA. Mod. Pathol., 29(4):347-58, 2016.

Coussens, L. M. \& Werb, Z. Inflammation and cancer. Nature, 420(6917):860-7, 2002.

Fernandez-Flores, A. Plasma cell infiltrate in common acquired melanocytic nevus. Acta Dermatovenerol. Croat., 16(3):158-63, 2008.

Gentles, A. J.; Newman, A. M.; Liu, C. L.; Bratman, S. V.; Feng, W.; Kim, D.; Nair, V. S.; Xu, Y.; Khuong, A.; Hoang, C. D.; et al. The prognostic landscape of genes and infiltrating immune cells across human cancers. Nat. Med., 21(8):938-45, 2015.

Guillerey, C.; Huntington, N. D. \& Smyth, M. J. Targeting natural killer cells in cancer immunotherapy. Nat. Immunol., 17(9):1025-36, 2016.

Hendry, S.; Salgado, R.; Gevaert, T.; Russell, P. A.; John, T.; Thapa, B.; Christie, M.; van de Vijver, K.; Estrada, M. V.; Gonzalez-Ericsson, P. I.; et al. Assessing tumor infiltrating lymphocytes in solid tumors: a practical review for pathologists and proposal for a standardized method from the International Immuno-Oncology Biomarkers Working Group: Part 2: TILs in melanoma, gastrointestinal tract carcinomas, non-small cell lung carcinoma and mesothelioma, endometrial and ovarian carcinomas, squamous cell carcinoma of the head and neck, genitourinary carcinomas, and primary brain tumors. Adv. Anat. Pathol., 24(6):311-35, 2017a.

Hendry, S.; Salgado, R.; Gevaert, T.; Russell, P. A.; John, T.; Thapa, B.; Christie, M.; van de Vijver, K.; Estrada, M. V.; Gonzalez-Ericsson, P. I.; et al. Assessing tumor infiltrating lymphocytes in solid tumors: a practical review for pathologists and proposal for a standardized method from the International Immuno-Oncology Biomarkers Working Group: Part 1: Assessing the host immune response, TILs in invasive breast carcinoma and ductal carcinoma in situ, metastatic tumor deposits and areas for further research. Adv. Anat. Pathol., 24(5):235-51, $2017 \mathrm{~b}$.

Klauschen, F.; Müller, K. R.; Binder, A.; Bockmayr, M.; Hägele, M.; Seegerer, P.; Wienert, S.; Pruneri, G.; de Maria, S.; Badve, S.; et al. Scoring of tumor-infiltrating lymphocytes: From visual estimation to machine learning. Semin. Cancer Biol., 52(Pt. 2):151-7, 2018

Lee, N.; Zakka, L. R.; Mihm Jr., M. C. \& Schatton, T. Tumour-infiltrating lymphocytes in melanoma prognosis and cancer immunotherapy. Pathology, 48(2):177-87, 2016.

Mantovani, A.; Allavena, P.; Sica, A. \& Balkwill, F. Cancer-related inflammation. Nature, 454(7203):436-44, 2008

Mishalian, I.; Granot, Z. \& Fridlender, Z. G. The diversity of circulating neutrophils in cancer. Immunobiology, 222(1):82-8, 2017.

Moreira, A.; Leisgang, W.; Schuler, G. \& Heinzerling, L. Eosinophilic count as a biomarker for prognosis of melanoma patients and its importance in the response to immunotherapy. Immunotherapy, 9(2):115-21, 2017.
Nelson, B. H. CD20+ B cells: the other tumor-infiltrating lymphocytes. $J$. Immunol., 185(9):4977-82, 2010.

Nielsen, S. R. \& Schmid, M. C. Macrophages as key drivers of cancer progression and metastasis. Mediators Inflamm., 2017:9624760, 2017.

Ribas, A. \& Wolchok, J. D. Cancer immunotherapy using checkpoint blockade. Science, 359(6382):1350-5, 2018.

Schatton, T.; Scolyer, R. A.; Thompson, J. F. \& Mihm Jr., M. C. Tumorinfiltrating lymphocytes and their significance in melanoma prognosis. Methods Mol. Biol., 1102:287-324, 2014.

Schmidt, H.; Bastholt, L.; Geertsen, P.; Christensen, I. J.; Larsen, S.; Gehl, J. \& von der Maase, H. Elevated neutrophil and monocyte counts in peripheral blood are associated with poor survival in patients with metastatic melanoma: a prognostic model. Br. J. Cancer, 93(3):273-8, 2005.

Scolyer, R. A.; Rawson, R. V.; Gershenwald, J. E.; Ferguson, P. M. \& Prieto, V. G. Melanoma pathology reporting and staging. Mod. Patbol., 33(Suppl. 1):15-24, 2020.

Shain AH, Yeh I, Kovalyshyn I, Sriharan A, Talevich E, Gagnon A, Dummer R, North J, Pincus L, Ruben B, Rickaby W, D'Arrigo C, Robson A, Bastian BC. The Genetic Evolution of Melanoma from Precursor Lesions. N. Engl. J. Med., 373(20):1926-36, 2015.

Shaul, M. E. \& Fridlender, Z. G. Tumour-associated neutrophils in patients with cancer. Nat. Rev. Clin. Oncol., 16(10):601-20, 2019.

Tucci, M.; Passarelli, A.; Mannavola, F.; Felici, C.; Stucci, L. S.; Cives, M. \& Silvestris, F. Immune system evasion as hallmark of melanoma progression: the role of dendritic cells. Front. Oncol., 9:1148, 2019.

Uribe-Querol, E. \& Rosales, C. Neutrophils in cancer: two sides of the same coin. J. Immunol. Res., 2015:983698, 2015.

Varricchi, G.; Galdiero, M. R.; Loffredo, S.; Lucarini, V.; Marone, G.; Mattei, F.; Marone, G. \& Schiavoni, G. Eosinophils: The unsung heroes in cancer? Oncoimmunology, 7(2):e1393134, 2017a.

Varricchi, G.; Galdiero, M. R.; Marone, G.; Granata, F.; Borriello, F. \& Marone, G. Controversial role of mast cells in skin cancers. Exp. Dermatol., 26(1):11-7, 2017b.

von Wasielewski, R.; Seth, S.; Franklin, J.; Fischer, R.; Hübner, K.; Hansmann, M. L.; Diehl, V. \& Georgii, A. Tissue eosinophilia correlates strongly with poor prognosis in nodular sclerosing Hodgkin's disease, allowing for known prognostic factors. Blood, 95(4):1207-13, 2000.

Weide, B.; Martens, A.; Hassel, J. C.; Berking, C.; Postow, M. A.; Bisschop, K.; Simeone, E.; Mangana, J.; Schilling, B.; Di Giacomo, A. M.; et al. Baseline biomarkers for outcome of melanoma patients treated with pembrolizumab. Clin. Cancer Res., 22(22):5487-96, 2016.

Wong, P. F.; Wei, W.; Smithy, J. W.; Acs, B.; Toki, M. I.; Blenman, K. R. M.; Zelterman, D.; Kluger, H. M. \& Rimm, D. L. Multiplex quantitative analysis of tumor-infiltrating lymphocytes and immunotherapy outcome in metastatic melanoma. Clin. Cancer Res., 25(8):2442-9, 2019.

Xie, F.; Liu, L. B.; Shang, W. Q.; Chang, K. K.; Meng, Y. H.; Mei, J.; Yu, J. J.; Li, D. J. \& Li, M. Q. The infiltration and functional regulation of eosinophils induced by TSLP promote the proliferation of cervical cancer cell. Cancer Lett., 364(2):106-17, 2015.

\section{Corresponding author:}

Alessio Giubellino, MD PhD

University of Minnesota

Department of Laboratory Medicine and Pathology

420 Delaware St. SE, C516 Mayo

Minneapolis, MN, 55455

UNITED STATES

E-mail: agiubell@umn.edu

Received: 28-09-2020

Accepted: $30-12-2020$ 